\title{
PPARס regulates satellite cell proliferation and skeletal muscle regeneration
}

\author{
Alison R Angione', Chunhui Jiang ${ }^{1}$, Dongning Pan², Yong-Xu Wang ${ }^{2}$ and Shihuan Kuang ${ }^{1,3^{*}}$
}

\begin{abstract}
Peroxisome proliferator-activated receptors (PPARs) are a class of nuclear receptors that play important roles in development and energy metabolism. Whereas PPAR $\delta$ has been shown to regulate mitochondrial biosynthesis and slow-muscle fiber types, its function in skeletal muscle progenitors (satellite cells) is unknown. Since constitutive mutation of Ppar $\delta$ leads to embryonic lethality, we sought to address this question by conditional knockout (cKO) of Ppar $\delta$ using Myf5-Cre/Ppar $\delta^{\text {flox/flox }}$ alleles to ablate PPAR $\delta$ in myogenic progenitor cells. Although Ppar $\delta$-cKO mice were born normally and initially displayed no difference in body weight, muscle size or muscle composition, they later developed metabolic syndrome, which manifested as increased body weight and reduced response to glucose challenge at age nine months. Ppar $\delta$-cKO mice had 40\% fewer satellite cells than their wild-type littermates, and these satellite cells exhibited reduced growth kinetics and proliferation in vitro. Furthermore, regeneration of Ppar $\delta$-cKO muscles was impaired after cardiotoxin-induced injury. Gene expression analysis showed reduced expression of the Forkhead box class $O$ transcription factor 1 (FoxO1) gene in Ppar $\delta$-cKO muscles under both quiescent and regenerating conditions, suggesting that PPAR $\delta$ acts through FoxO1 in regulating muscle progenitor cells. These results support a function of PPAR $\delta$ in regulating skeletal muscle metabolism and insulin sensitivity, and they establish a novel role of PPAR $\delta$ in muscle progenitor cells and postnatal muscle regeneration.
\end{abstract}

Keywords: Cre/LoxP, skeletal muscle, stem cell, proliferation, differentiation, self-renewal

\section{Background}

Skeletal muscle is the most abundant tissue in mammals, making up $45 \%$ to $55 \%$ of total body mass in humans, and plays important roles in body movement and metabolic regulation. Muscle is made up of different fiber types which have different metabolic requirements that affect the whole body energy homeostasis of the animal [1]. Type 1 fibers are classified as slow fibers and use oxidative metabolism as a fuel source, making them highly fatigue-resistant. Conversely, type 2 fibers are classified as fast fibers, use mainly glycolytic metabolism and are less resistant to fatigue. Type 2 fibers are further broken down into three subtypes, known as types $2 \mathrm{a}, 2 \mathrm{x}$ and $2 \mathrm{~b}$, that express corresponding myosin heavy chain $(\mathrm{MyHC})$ isoforms and have decreasing resistance to fatigue. Notably, skeletal muscles are plastic, and fiber-type switching occurs in response to changes in activity and

\footnotetext{
* Correspondence: skuang@purdue.edu

'Department of Animal Sciences, Purdue University, 901 West State Street, West Lafayette, IN 47907, USA

Full list of author information is available at the end of the article
}

other physiological signaling pathways [2-4]. In addition, skeletal muscle mass is always in a state of hypertrophy or wasting, based on relative use or disuse, respectively $[5,6]$. Skeletal muscle has superior capacity to regenerate itself upon injury [7].

Skeletal muscle plasticity is mainly maintained by a subset of cells known as satellite cells $[8,9]$. These cells, located beneath the basal lamina of the muscle fiber, are normally maintained in a quiescent state. Satellite cells become activated when the muscle becomes damaged through injury or normal activity. Once activated the cells will reenter the cell cycle and undergo a few rounds of division, then differentiate and fuse with existing muscle fibers to rebuild the damaged area. Satellite cells in the quiescent state express paired-box transcription factor 7 (Pax7) [10]. After activation the cells will express Pax7 and myogenic differentiation antigen 1 (MyoD) concurrently while the cells undergo a few rounds of division (proliferation). These proliferating cells eventually withdraw from the cell cycle and either return to 
quiescence (self-renewal) through downregulation of MyoD or differentiate through downregulation of Pax7 and upregulation of myogenin. Thus expression of Pax7 and MyoD distinguishes the status of a cell, whether it is self-renewing $\left(\mathrm{Pax}^{+} / \mathrm{MyoD}^{-}\right)$, proliferating $\left(\mathrm{Pax}^{+} / \mathrm{MyoD}^{+}\right)$or differentiating $\left(\mathrm{Pax}^{-} / \mathrm{MyoD}^{+}\right)$, respectively [11-13]. Notably, researchers in several recent studies have demonstrated that the choice between self-renewal and differentiation of newly divided satellite cells is dynamically regulated [14-16]. Whereas most proliferating myoblasts divide symmetrically, a subpopulation of cells can divide asymmetrically to give rise to both self-renewal and differentiating progenies [14-16].

Myogenic factor 5 (Myf5) is also important for skeletal muscle development and satellite cell function. Myf5 transcripts can first be detected at E8 in the developing embryo and are important for specifying the cells of the muscle lineage [17]. Myf5-Cre lineage tracing labels a majority of satellite cells, which will have become committed to the myogenic lineage. However, $10 \%$ of satellite cells remain Myf5-negative and are thought to be a population of more primitive, uncommitted stem cells that can give rise to committed cells through asymmetric cell division [15]. Myf5-null satellite cells are defective in transient proliferation prior to differentiation $[18,19]$. Intriguingly, investigators in recent studies have demonstrated that brown adipocytes, but not white adipocytes, are derived from Myf5 lineage progenitors [20]. Therefore, Myf5-Cre-mediated conditional knockout can be used to knock out floxed target genes in committed myogenic progenitor cells and their descendants (mature skeletal muscles) as well as in brown adipocytes.

Peroxisome proliferator-activated receptors (PPARs) are members of the nuclear estrogen receptor superfamily and have been shown to be important for the proper metabolism of fatty acids [21]. There are three PPAR isoforms $(\alpha, \delta$ and $\gamma)$, and each plays a specific role in metabolism [22-24]. The PPARs are expressed in a wide range of adult tissues, but each has its own tissue-specific expression patterns. PPAR $\alpha$ is highly expressed in the liver and heart, PPAR $\delta$ (also referred to as PPAR $\beta$, $\mathrm{PPAR} \beta / \delta$ or NR1C2) is highly expressed in the intestine and liver, and PPAR $\gamma$ is highly expressed in both brown and white adipose tissues [21-23,25,26]. The three PPAR isoforms are ligand-activated receptors that are activated by fatty acids, fatty acid derivatives and a variety of synthetic compounds [21]. The ligand-binding domains of PPARs vary slightly, resulting in specific affinity for fatty acids and synthetic compounds [27]. For example, GW501516 is one synthetic compound that has been shown to specifically activate PPAR $\delta$ with 60 - to 1,000 fold selectivity over the other isoforms, depending on cell types and animal species $[28,29]$. These receptors must form heterodimers with the retinoid $\mathrm{X}$ receptor (RXR) before they can bind to specific recognition sequences, called PPAR response elements (PPREs), which are located in the promoter and intron regions of a wide variety of target genes $[21,30]$. The PPARs activate or repress transcription through the recruitment of coactivators and corepressors.

PPAR $\delta$ has been shown to be important for the proper function of skeletal muscle in gain- and loss-of-function studies. Synthetic compound-mediated activation or overexpression of the Ppar $\delta$ gene in mice causes an increase in the oxidative capacity of the muscle resulting from an increase in the number of type 1 oxidative fibers and a decrease in the number of type 2 glycolytic fibers [31,32]. These increases in oxidative capacity have been shown to contribute to an organism's overall exercise endurance. Along with increases in oxidative capacity, transgenic mice also show a decrease in overall body fat content and individual adipocyte size. Mice with constitutively active Ppar $\delta$ can maintain a normal body weight even when challenged with a high-fat diet, whereas their wild-type littermates become obese when fed the same diet. By contrast, skeletal muscle-specific knockout of Ppard seems to cause a decrease in oxidative capacity and makes mice prone to obesity and metabolic disorders [33]. This loss of oxidative capacity could be due in part to reduced expression of PGC1 $\alpha$, which is known to play a role in type 1 fiber formation and maintenance. These results suggest that PPAR $\delta$ plays a role in preventing obesity and the development of metabolic disorders.

Until now all the studies on PPAR $\delta$ in skeletal muscle have focused on mature muscle fibers. It remains to be determined whether PPAR $\delta$ plays a role in myogenic satellite cells and postnatal muscle regeneration. PPAR $\delta$ has been shown to regulate the proliferation and/or maturation of several cell types, including mouse embryonic stem cells, oligodendrocytes, keratinocytes, endothelial progenitors and cancer cells [34-38]. However, whether PPAR $\delta$ positively or negatively regulates proliferation is highly cell type-specific, and the evidence presented in the literature has sometimes been contradictory [36]. In the current study, we used a Cre/LoxPbased conditional mutation approach to remove Ppar $\delta$ from the satellite cells to examine its function in muscle progenitor cells. We show herein that PPAR $\delta$ is an important regulator of satellite cell proliferation in vitro and of muscle regeneration in vivo.

\section{Materials and methods \\ Animals}

All experimental procedures involving the use of mice were carried out in accordance with Purdue University's 
Animal Care and Use Committee. C57BL/6J mice containing LoxP sites flanking exon 4, which encodes the $\mathrm{N}$-terminal zinc finger of the DNA-binding domain of the Ppar $\delta$ gene $\left(\right.$ Ppar $\left.^{\mathrm{f} / \mathrm{f}}\right)$, had been generated previously [39]. These mice were crossed with Myf5-Cre to generate Myf5-Cre/Ppar $\delta^{\mathrm{f} / \mathrm{f}}$ offspring for ablation of Ppar $\delta$ in Myf5 lineage cells (called "Ppar $\delta$-cKO" hereinafter) [40]. $\operatorname{Ppar}^{+/ \mathrm{f}}$ or $P$ par $\delta^{\mathrm{f} / \mathrm{f}}$ littermates that did not inherit the Myf5-Cre allele were used as controls (called "wild type" hereinafter, as these mice express Ppar $\delta$ normally). Genotyping was done by PCR to confirm the presence of Cre along with the presence of floxed and wild-type Ppar $\delta$ alleles as described by The Jackson Laboratory under mouse stock numbers 007893 and 005897 (Bar Harbor, ME, USA).

\section{Cardiotoxin injection}

Tibilais anterior (TA) muscles taken from six-week-old C57BL/6J mice were injured by injection of cardiotoxin (CTX) (C3987; Sigma-Aldrich, St Louis, MO, USA) to induce muscle regeneration. The animals were first anesthetized by intraperitoneal injection of $0.2 \mathrm{ml}$ ketamine cocktail/20 g body weight. Ketamine cocktail contains $0.9 \mathrm{ml}$ of ketamine $(100 \mathrm{mg} / \mathrm{ml}), 0.1 \mathrm{ml}$ of xylazine $(100 \mathrm{mg} / \mathrm{ml})$ and $9.0 \mathrm{ml}$ of saline. The hind limbs were then shaved to expose the belly of the TA and wiped with $70 \%$ ethanol. Next we injected $50 \mu \mathrm{l}$ of $10 \mu \mathrm{M}$ CTX into the belly of the TA muscle. The mice were allowed to recover on a heating pad for about one hour. The mice were then harvested at days 5 and 14 after injection, and their TA muscles were removed for RNA extraction and histological examination after being fixed in $4 \%$ paraformaldehyde.

\section{Glucose challenge}

Glucose tolerance tests were performed on two- and nine-month-old mice. All mice were fasted for three hours prior to the start of testing. Blood was collected from the tip of the tail and tested before ( 0 minutes) and 15, 30, 60 and 90 minutes after intraperitoneal injection of glucose $(2 \mathrm{~g} / \mathrm{kg})$. Blood glucose levels were measured using an ACCU-CHEK Active blood glucose meter system (Roche Diagnostics, Indianapolis, IN, USA). Body weight data were collected prior to glucose tolerance testing.

\section{Cell culture}

Primary myoblasts were harvested from the limb muscles of mice that were six weeks of age. Limb muscles were digested in a solution containing $1 \%$ collagenase B (Roche Diagnostics) and 2.4 U/ml Dispase II (neutral protease, grade II; Roche Applied Science) for $30 \mathrm{~min}$ utes in an incubator at $37^{\circ} \mathrm{C}$ with $5 \% \mathrm{CO}_{2}$ and triturated every 15 minutes. The digestion was stopped after 30 minutes using $25 \mathrm{ml}$ of DMEM containing 2\% fetal bovine serum (FBS) and $10 \mathrm{mM}$ 4-(2-hydroxyethyl)-1piperazineethanesulfonic acid, then passed through a $100-\mu \mathrm{m}$ filter. After filtration, the cells and muscle debris were pelleted at $250 \times g$ for five minutes and the DMEM was removed. The cells and muscle debris were then plated on noncoated plates with Ham's complete medium containing 20\% FBS, $4 \mathrm{ng} / \mathrm{ml}$ basic fibroblast growth factor and $1 \%$ penicillin/streptomycin $(\mathrm{p} / \mathrm{s})(10$, $000 \mathrm{U}$ penicillin $/ \mathrm{g} / \mathrm{ml}, 10 \mathrm{mg}$ streptomycin $/ \mathrm{ml}$ ). The cells and muscle debris were maintained in an incubator at $37^{\circ} \mathrm{C}$ with $5 \% \mathrm{CO}_{2}$ for three days, and $5 \mathrm{ml}$ of Ham's medium were added each day. On the third day, all cells and muscle debris (with cells attached) were collected into a $15-\mathrm{ml}$ conical tube and digested with $1 \mathrm{ml}$ of $0.025 \%$ trypsin for five minutes at $37^{\circ} \mathrm{C}$. Dissociated cells were resuspended in $10 \mathrm{ml}$ of Ham's complete medium and passed through a $30-\mu \mathrm{m}$ filter, then plated on a collagen-coated plate. Myoblasts were maintained in Ham's medium and passed through the filter several times before they became senescent and were discarded. To differentiate myoblasts, Ham's medium was switched to DMEM containing 5\% horse serum with $1 \% \mathrm{p} / \mathrm{s}$ when cultures reach $80 \%$ confluence. For cell-growth analysis, primary myoblasts from both Ppar $\delta$-cKO and wild-type mice were counted, and 50, 000 cells were seeded into each well of a six-well plate. Cells were removed from the plate with trypsin and counted with a hemocytometer on days 3, 6 and 9 after the initial plating.

\section{Isolation and culture of single myofibers}

Single myofiber-carrying satellite cells were isolated as previously described [41]. Fibers were harvested from the soleus (SOL) and extensor digitorum longus (EDL) muscles of mice that were six weeks of age. Whole muscles were removed from the hind limbs by careful handling of the tendons only. The SOL and EDL muscles were first placed in $5 \mathrm{ml}$ of DMEM containing $0.2 \%$ collagenase I and then into the water bath at $37^{\circ} \mathrm{C}$ for 40 minutes (EDL muscle) or 80 minutes (SOL muscle). The fibers were then placed into a $6-\mathrm{cm}$ plate with $5 \mathrm{ml}$ of DMEM and separated from the tendons by careful manipulation using heat-polished Pasteur pipettes coated with horse serum to prevent sticking. After the fibers were separated, they were fixed immediately for staining or transferred onto a new plate containing $5 \mathrm{ml}$ of DMEM with $20 \% \mathrm{FBS}$ and $2 \%$ chick embryo extract, then placed in the incubator at $37^{\circ} \mathrm{C}$ with $5 \% \mathrm{CO}_{2}$ for three days. At the end of the three days, the fibers were collected, fixed with $2 \%$ paraformaldehyde and prepared for staining.

\section{Immunocytochemistry}

Primary myoblasts were grown in chamber slides for staining. The cells were fixed with $2 \%$ paraformaldehyde 
for ten minutes, then washed three times with PBS before the primary antibody was added. The primary antibodies used were Pax7 (Developmental Studies Hybridoma Bank, Department of Biology, University of Iowa, Iowa City, IA USA), MyoD (sc-20; Santa Cruz Biotechnology, Santa Cruz, CA, USA), and mAb clones HB287, HB277 and HB283 for MyHC1, MyHC2a and MyHC2b, respectively (American Type Culture Collection, Manassas, VA, USA). Cells were incubated with the primary antibody for one hour at room temperature on a shaker. After incubation with the primary antibody, the cells were washed three times with PBS before the secondary antibody was added. The secondary antibodies used were goat anti-mouse immunoglobulin G2b (IgG2b) conjugated with Alexa Fluor 647 dye, goat antimouse IgG1 conjugated with Alexa Fluor 568 dye, goat anti-mouse IgM conjugated with Alexa Fluor 488 dye (Molecular Probes/Life Technologies, Carlsbad, CA, USA) and daylight Alexa Fluor 488-conjugated goat anti-rabbit (Jackson ImmunoResearch Laboratories, Inc, West Grove, PA, USA). The cells were incubated with secondary antibody and Hoechst dye (a DNA dye) for 30 minutes. The cells were again washed three times with PBS before being mounted with Dako Fluorescence Mounting Medium (Glostrup, Denmark) and covered with a coverslip. Images were recorded on a Leica DMI6000 B inverted fluorescence microscope (Leica Microsystems, Mannheim, Germany).

\section{Histology}

The muscles harvested from the hind limbs were embedded in optimal cutting temperature (O.C.T.) compound (Sakura Finetek USA Inc, Torrance, CA, USA) and quickly frozen in dry ice-cooled isopentane. Cryosections were cut to $10-\mu \mathrm{m}$ thickness and placed on glass slides. For immunohistochemistry, slides were blocked with blocking buffer (5\% horse serum, 2\% BSA, $0.2 \%$ Triton $\mathrm{X}-100$ and $0.1 \%$ sodium azide in PBS) for two hours prior to antibody staining. The slides were incubated with primary antibodies for one hour at room temperature, then washed three times with PBS before incubation with secondary antibody for 30 minutes. After three more washes with PBS, the slides were mounted with Dako Fluorescence Mounting Medium and covered with a coverslip.

\section{$H$ \& $E$ and NADH staining}

Sections $(10-\mu \mathrm{m}$ thickness) were first washed with PBS to remove excess O.C.T. compound, then incubated in hematoxylin for five minutes, washed and incubated in $1 \%$ eosin for 30 seconds. The sections were then dehydrated in increasing concentrations of ethanol and mounted with CytoSeal Mounting Medium (Electron Microscopy Sciences, Fort Washington, PA, USA), covered with a coverslip and allowed to dry overnight. For nicotinamide adenine dinucleotide, reduced (NADH) staining, sections were washed briefly in PBS to remove excess O.C.T. compound. The slides were then incubated in a solution containing $100 \mathrm{mg} / \mathrm{ml}$ $\mathrm{NADH}$ and $0.1 \mathrm{~g} / \mathrm{ml}$ nitroblue tetrazolium (NBT) for 30 minutes at $37^{\circ} \mathrm{C}$. The slides were then washed three times with deionized water. Unbound NBT was removed from the sections by washing the slides three times each with $30 \%, 60 \%$ and $90 \%$ acetone. The sections were then washed with deionized water and mounted.

\section{Gene expression}

All gene expression data were gathered by real-time PCR. RNA was extracted from cell culture, whole-muscle and adipose tissue using the RNeasy RNA extraction kit (QIAGEN, Germantown, MD, USA). RNA was converted into cDNA using Moloney murine leukemia virus reverse transcriptase and random hexamer primers. The real-time PCR oligonucleotides are listed in Additional file 1, Table S1. Samples were then run in a LightCycler 480 System (Roche Applied Science) for 40 cycles. Fold changes were calculated using the $2^{-\Delta \Delta \mathrm{Ct}}$ method.

\section{Western blot analysis}

Expression of PPAR $\delta$ protein in Ppar $\delta$-cKO and wildtype muscles was examined by Western blot analysis as previously described [32]. Briefly, equal amounts of nuclear proteins extracted under identical conditions were run on SDS-PAGE gels and transferred onto polyvinylidene difluoride membrane. PPAR $\delta$ was detected with rabbit anti-PPAR $\delta$ antibody from Santa Cruz Biotechnology (SC-7197).

\section{Statistical analysis}

The number of mice used for each experiment is listed in the figure legend. Every experiment was performed in triplicate. For the glucose tolerance tests, statistical analysis was based on area under the curve (AUC) using the trapezoidal rule. All data are presented as means \pm SEM. $P$-values were calculated using a two-tailed Student's $t$-test unless otherwise indicated. All values equal to 0.05 or less were considered significant and are denoted by asterisks in the figures.

\section{Results}

\section{Characterization of the Ppar $\delta$-cKO model}

To generate tissue-specific knockout of Ppar $\delta$, we used mice bearing a floxed exon 4 in the Ppar $\delta$ gene [39]. The presence of Cre will excise exon 4, corresponding to the $\mathrm{N}$-terminal zinc finger of the DNA binding domain of PPAR $\delta$, and lead to premature stop of translation and abolish the transcriptional activity of the resulting truncated PPAR $\delta$ (Additional file 2, Figure 
S1A). The Pparf $f^{f / f}$ mice were bred to mice expressing Cre recombinase under the control of the endogenous Myf5 promoter Myf5-Cre (007893; The Jackson Laboratory) to generate the Ppar $\delta$-cKO mice. Since $M y f 5$ is expressed in the mesoderm during development, we expected that PPAR $\delta$ would be selectively ablated in several mesodermal tissues that express $M y f 5$, including skeletal muscle and brown fat (BAT) [20].
To confirm the tissue-specific knockout, we collected RNA samples from adult skeletal muscle, BAT and white fat (WAT) and conducted quantitative RT-PCR (qPCR) analysis. The levels of Ppar $\delta$ in the Ppar $\delta$-cKO mice compared to their wild-type littermates were reduced by 7 -fold in TA muscle and by 11 -fold in BAT, but they were not changed in WAT (Figure 1A). These results confirm the tissue-specific knockout and are

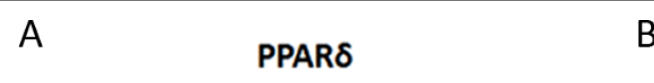

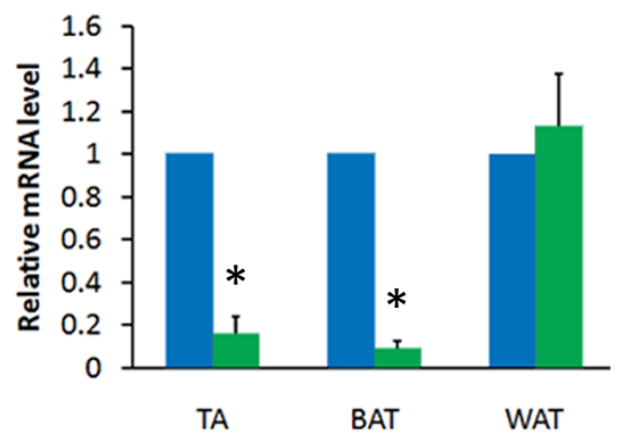

PPAR $\alpha$
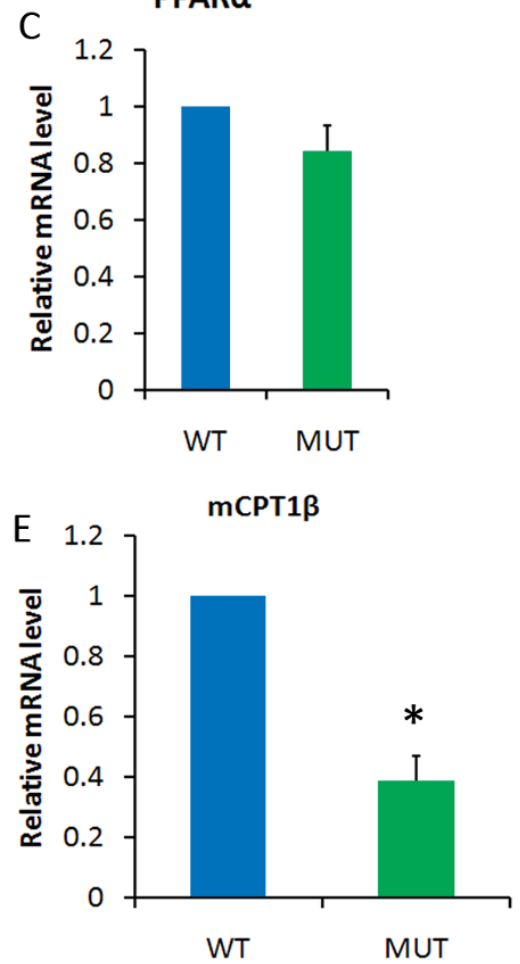

B

PPAR $\delta$
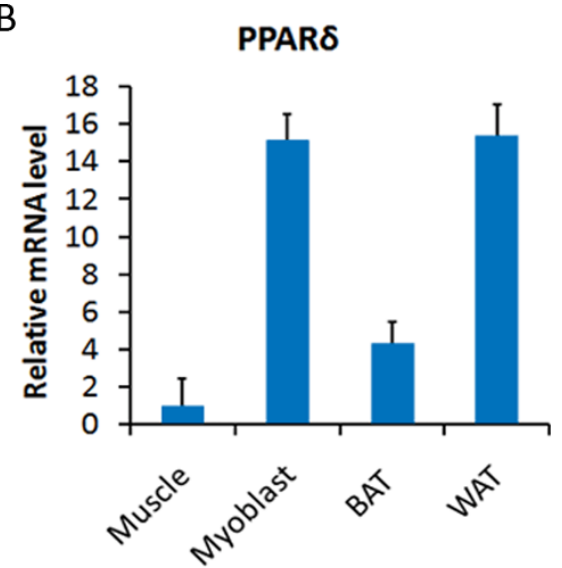

PPARY
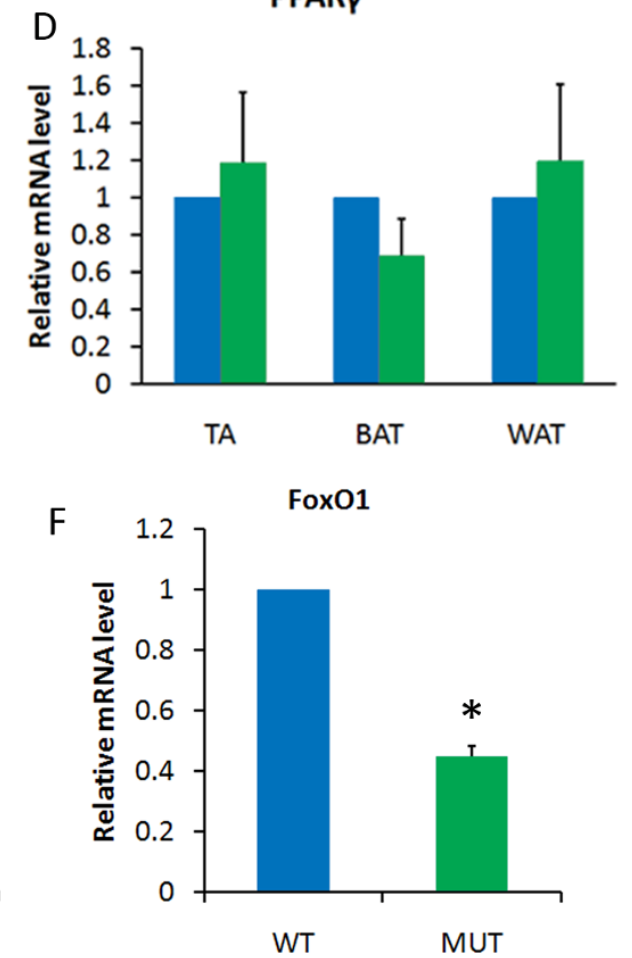

Figure 1 Characterization of the PPAR $\boldsymbol{\delta}$-cKO model. Blue and green bars represent wild-type (WT) and peroxisome proliferator-activated receptor $\delta$ conditional knockout (Ppar $\delta$-cKO) (MUT) tissues, respectively. (A) Relative expression levels of Ppar $\delta$ in tibialis anterior (TA) muscle, brown fat and white fat tissues ( $N=8$ pairs of wild-type and mutant mice) for each tissue type. (B) Quantitative RT-PCR showing the relative expression levels of Ppar $\delta$ in whole-muscle tissue, proliferating myoblasts, white fat and brown fat in wild-type mice $(N=8$ for each tissue type and $N=2$ for myoblasts). (C) and (D) Expression levels of Ppar $\alpha$ in TA muscle (C) and Ppary in TA, brown fat and white fat tissues ( $N=8$ for each tissue type) (D). (E) and (F) Expression levels of carnitine palmitoyltransferase $1 \beta$ ( $m C P T 1 \beta)$ and Forkhead box class $O$ transcription factor 1 (FoxO1) genes in TA muscles $(N=3)$. 
consistent with the notion that skeletal muscle and BAT derive from the Myf5 lineage and WAT derives from a Myf5-independent lineage [20]. We further confirmed by Western blot analysis that PPAR $\delta$ protein levels are reduced by $60 \%$ to $80 \%$ in the gastrocnemius muscles of Ppar $\delta$-cKO mice compared to those of wild-type mice (Additional file 2, Figure S1B). Interestingly, analysis of relative Ppar $\delta$ expression in various wild-type tissues indicated that both proliferating myoblasts (derived from satellite cells) and WAT expressed much higher levels of Ppar $\delta$ compared to whole muscle and BAT (Figure 1B). Specifically, Ppar $\delta$ mRNA levels in primary myoblasts were about 15 -fold greater than those in the TA muscles, suggesting a specific role of PPAR $\delta$ in myoblast proliferation. In addition, we found that the levels of Ppary and Pparo remained unchanged in Ppar $\delta$-cKO compared to wild-type tissues (Figures $1 \mathrm{C}$ and 1D), confirming that Ppar $\delta$-cKO did not elicit compensation by other PPAR isoforms. Therefore, any observed phenotypes are due to specific knockout of Ppard in our mouse model.

To understand how PPAR $\delta$ functions in muscle, we compared the expression of a number of known PPAR $\delta$ target genes in wild-type and mutant TA muscles from adult mice. The expression of carnitine palmitoyltransferase $1 \beta(m C P T 1 \beta)$, whose protein regulates the ratelimiting step for $\beta$-oxidation of long-chain fatty acids $[21,24]$, and Forkhead box class $O$ transcription factor 1 (FoxO1), a PPAR $\delta$ target that regulates skeletal muscle metabolism and progenitor cell function [42-44], were significantly decreased in Ppar $\delta$-cKO muscle (Figures $1 \mathrm{E}$ and $1 \mathrm{~F}$ ). The expression of several other known target genes of PPAR $\delta$, including Sirt1, UCP1 and PGC1 $\alpha$, was not altered in the mutant muscles (Additional file 3, Figure S2). These results confirm that Ppar $\delta$-cKO affects candidate target gene expression and identify $m C P T 1 \beta$ and FoxO1 as potential target genes regulated by PPAR $\delta$ in resting skeletal muscles.

\section{Satellite cell and myoblast proliferation and differentiation}

Adult Ppar $\delta$-cKO mice have a reduced number of satellite cells, and Ppar $\delta$-null myoblasts exhibited reduced proliferation and increased differentiation kinetics. Because proliferating myoblasts expressed high levels of Ppar $\delta$ compared to whole muscles (Figure 1B), we investigated the effect of Ppar $\delta$ mutation on the satellite cells in vivo and in myoblasts in culture. Intact single fibers were isolated from the representative slow (SOL) and fast (EDL) muscles and stained with Pax7 antibody to label satellite cells (Figure 2A). At two to three months old, the mutant mice had, on average, a $40 \%$ reduction in satellite cell numbers in both EDL and SOL muscles (Figure 2C). Consistent with this observation, qPCR analysis indicated that satellite cellspecific Pax7 gene expression was reduced by about $40 \%$ in the mutant compared to the wild-type TA muscles (Figure 2D). Interestingly, normal satellite cell numbers were detected at three weeks of age, and a nearly $20 \%$ reduction was detected at age five weeks in the Ppar $\delta$-cKO compared to the wild-type EDL fibers (Additional file 4, Figure S3). Furthermore, the number of 4', 6-diamidino-2-phenylindole-positive nuclei per myofiber was reduced in the Ppar $\delta$-cKO mice at five weeks old but not at three weeks old (Additional file 4, Figure S3). The gradual reduction in satellite cells and differentiated myonuclei in the Ppar $\delta$-cKO muscle during postnatal growth suggests that $\mathrm{PPAR} \delta$ is important for satellite cell proliferation and maintenance.

Next we examined whether the satellite cells associated with the isolated fibers were able to proliferate and differentiate normally using a single-myofiber culture paradigm to mimic satellite cell activation in vivo $[13,15]$. We cultured isolated fibers for three days in vitro and fixed and stained clusters of myoblasts that had proliferated on single fibers with antibodies to Pax7 and MyoD (Figure 2B). Previous studies have established that $\mathrm{Pax}^{+} / \mathrm{MyoD}^{-}, \mathrm{Pax}^{+} / \mathrm{MyoD}^{+}$and $\mathrm{Pax} 7^{-} / \mathrm{MyoD}^{+}$ cells represent self-renewing, proliferating and differentiating progenies, respectively [11-13]. The relative percentage of cells in these three categories was examined. Compared to the wild type, mutant SOL fibers had half as many proliferating cells $\left(\operatorname{Pax} 7^{+} / \mathrm{MyoD}^{+}\right)$and twice as many differentiating cells $\left(\mathrm{MyoD}^{+}\right)$, whereas the proportion of self-renewing cells $\left(\operatorname{Pax} 7^{+}\right)$remained the same between wild-type and mutant fibers (Figure 2E). Together, these results show that PPAR $\delta$ is important for maintaining the proliferation of activated myoblasts and that loss of PPAR $\delta$ leads to accelerated myogenic differentiation.

To further characterize the proliferative defects of Ppar $\delta$-null myoblasts, we examined the expression of Ki67, a cell proliferation marker, in cultured primary myoblasts from mutant mice and wild-type littermates (Figure 3A-B). Real-time PCR analysis confirmed a $60 \%$ reduction in Ppar $\delta$ expression in newly established cultures of Ppar $\delta$-cKO compared to wild-type myoblasts (Additional file 5, Figure S4A). The percentage of $\mathrm{Ki}^{+} 7^{+}$ cells and the Ki67 immunofluorescence intensity of the Ppar $\delta$-mutant myoblasts were threefold less than those of wild-type plates (Figures 3C). Conversely, a PPAR $\delta$ agonist, GW501516, significantly increased wild-type myoblast proliferation (Additional file 5, Figure S4B). We also plotted the growth curve of wild-type and mutant myoblasts at days 3, 6 and 9 after they were plated in culture. Myoblasts from Ppar $\delta$-cKO muscle showed a reduced growth rate compared to myoblasts from wild-type muscle (Figure 3D). These results 

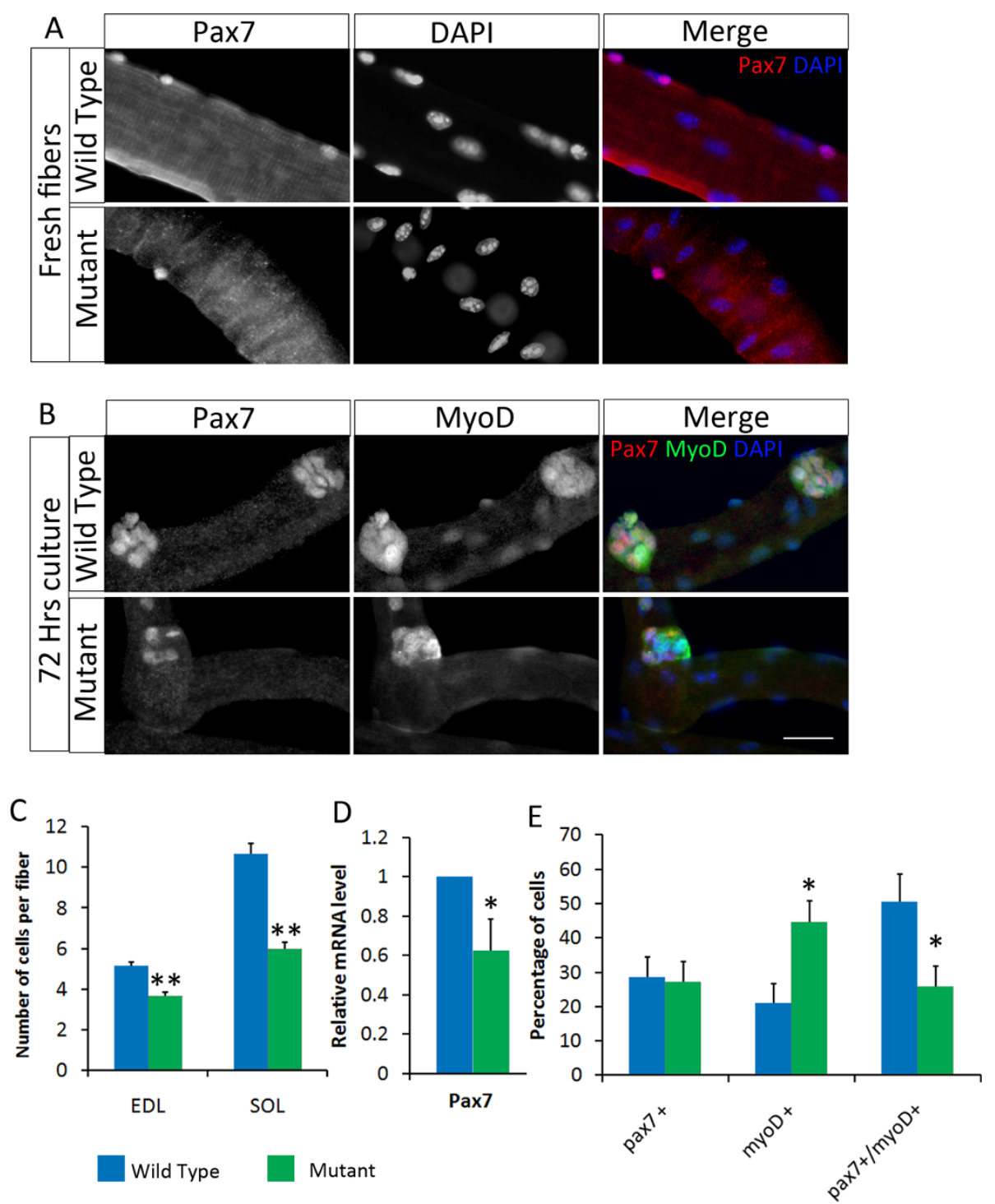

Figure 2 Reduced satellite cell number and proliferation in Ppar $\delta$-cKO mice. (A) Freshly isolated extensor digitorum longus (EDL) muscle fibers were stained with paired-box transcription factor 7 (Pax7) antibody to label satellite cells. Nuclei were counterstained with 4', 6-diamidino2-phenylindole (DAPI). Scale bar $=25 \mu \mathrm{m}$ for all panels in parts (A) and (B). (B) Soleus (SOL) muscle fibers were cultured for 72 hours, and the proliferating satellite cells on the fibers were fixed and stained with Pax7 and myogenic differentiation antigen 1 (MyoD) antibodies. Nuclei were counterstained with DAPI. Satellite cell status is classified as self-renewed cells $\left(\operatorname{Pax} 7^{+}\right)$, proliferating cells $\left(\operatorname{Pax} 7^{+} / \mathrm{MyoD}^{+}\right)$and differentiating cells $\left(\mathrm{MyoD}^{+}\right)$. (C) Quantification of the number of Pax $7^{+}$satellite cells per single fiber isolated from the EDL and SOL muscles ( $N=360$ fibers each from the SOL and EDL muscles). ${ }^{*} P<0.0001$. (D) Relative expression of the Pax7 gene in tibialis anterior (TA) muscles by quantitative PCR ( $N=$ 3). (E) Quantification of the number of self-renewed, proliferating and differentiating cells on SOL fibers after culture for 72 hours ( $N=20$ fibers for each group).

provide compelling evidence that PPAR $\delta$ positively regulates myoblast growth and proliferation.

\section{Muscle regeneration after injury is impaired in Ppar $\delta$-cKO animals}

To examine whether the reduced rates of proliferation in the Ppar $\delta$-cKO myoblasts result in defects in muscle regeneration in vivo, we injured the TA muscles of mutant and wild-type animals at six weeks of age. After
14 days, the mice were killed and the TA muscles were collected for gene expression and histological analysis. We examined the regenerating regions under a microscope, and the number of regenerating fibers (small, centrally located nucleus) and regenerated fibers (large, eccentrically located nucleus) were counted. Both wildtype and Ppar $\delta$-cKO TA muscles underwent regeneration, but they exhibited marked differences (Figures 4A and $4 \mathrm{~B})$. The mutant muscles had much larger areas of 


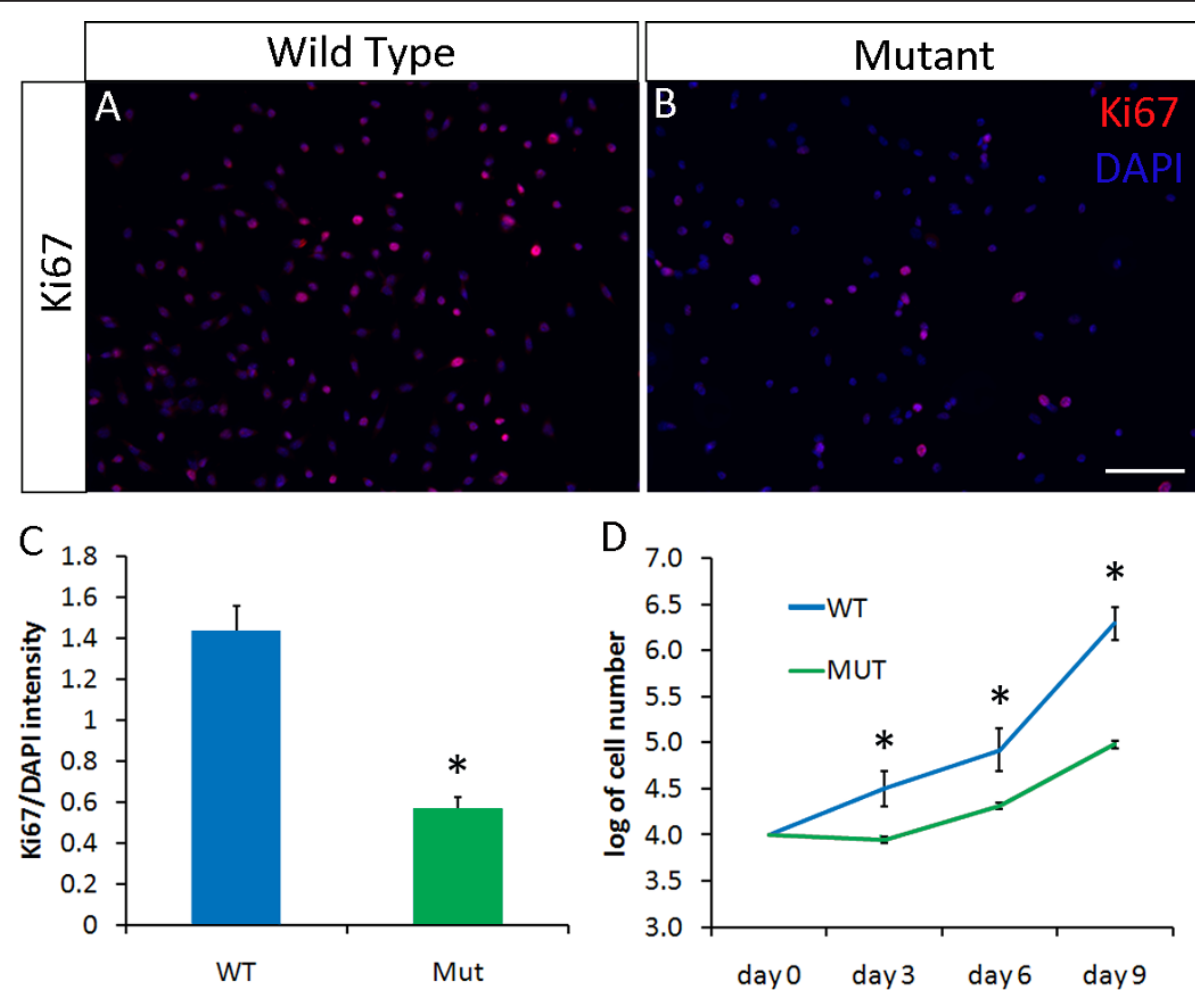

Figure 3 Defective growth and proliferation of primary myoblast cells derived from Ppar $\delta$-cKO muscles. (A) and (B) Representative images of Ki67 staining that specifically labeled proliferating primary myoblasts: Ki67 staining (red) and 4', 6-diamidino-2-phenylindole (DAPI) staining (blue). Scale bar $=50 \mu \mathrm{m}$. (C) Relative Ki67 signal intensity in wild-type and mutant myoblast cultures. The intensity of Ki67 and DAPI staining and the number of pixels were measured using Photoshop software (Adobe Systems Inc, San Jose, CA, USA). The ratio of Ki67 intensity values to DAPI intensity values was also quantified using Photoshop $(N=3)$. (D) Growth curve of wild-type and mutant myoblasts after nine days in culture $(N=3)$.

small-caliber regenerating fibers that covered almost the whole muscle sections, whereas the wild-type TA muscles had reduced regenerating areas that were mostly confined to the center of the section (Figures $4 \mathrm{~A}$ and 4B). The number of small regenerating fibers was $30 \%$ more, and the number of large regenerating fibers was $20 \%$ fewer, in Ppar $\delta$-cKO muscles compared to wildtype muscles (Figure $4 \mathrm{C}$ ). In addition, the regenerating Ppar $\delta$-cKO TA muscles expressed reduced levels of $M y H C 2 b$ mRNA, the most abundant MyHC isoform in the TA muscle (Figure 4D), which further confirms the regenerative defects. The Ppar $\delta$-cKO muscles were eventually able to regenerate after 30 days, suggesting that Ppar $\delta$-cKO mainly causes a delay in muscle regeneration.

Because Ppar $\delta$-cKO myoblasts are defective in proliferation in vitro, we sought to determine whether such defects exist in vivo during muscle regeneration. We analyzed Pax7 and MyoD expression (Figures $4 \mathrm{~F}$ and 4G) at days 3 to 5 post-CTX treatment, at which stage myoblast proliferation peaks. Consistent with our in vitro results, we observed a reduction of proliferating $\mathrm{Pax}^{+} / \mathrm{MyoD}^{+}$myoblasts and an increase in differentiated Pax7 $/ \mathrm{MyoD}^{+}$myocytes in the Ppar $\delta$-cKO muscle, together with reduced total myoblast number per unit area and decreased size of newly regenerated fibers (Figures $4 \mathrm{~F}$ to $4 \mathrm{I}$ ). In addition, we confirmed by qPCR that Myogenin gene expression was upregulated in regenerating Ppar $\delta$-cKO muscles at this stage (Figure $4 \mathrm{~J})$. By contrast, $M y f 5$ was expressed at similar levels in the mutant and wild-type muscles. These results indicate that the observed regenerative defects of PpardcKO may be due to reduced proliferation and increased differentiation kinetics of activated myoblasts.

We also examined the expression of $m C P T 1 \beta$ and FoxO1 genes during muscle regeneration at day 5 after CTX treatment, when damaged muscles are not yet regenerated and satellite cell proliferation peaks [8]. Interestingly, expression of $m C P T 1 \beta$ was unchanged but FoxO1 expression was reduced in the Ppar $\delta$-cKO muscles compared to wild-type muscles during muscle regeneration (Figure 4E), suggesting that PPAR $\delta$ may activate FoxO1 in proliferating myoblasts and that $m C P T 1 \beta$ is a PPAR $\delta$ target only in mature muscle fibers. Together with our earlier observation that Ppar $\delta$ is expressed at much higher levels in proliferating 


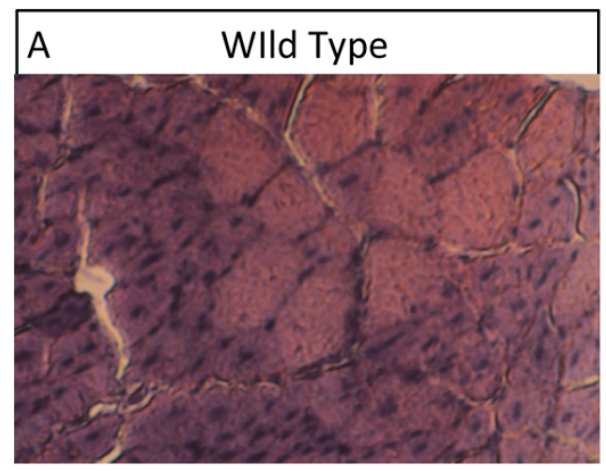

C

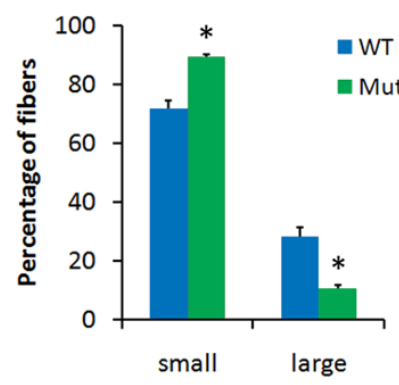

D
B Mutant
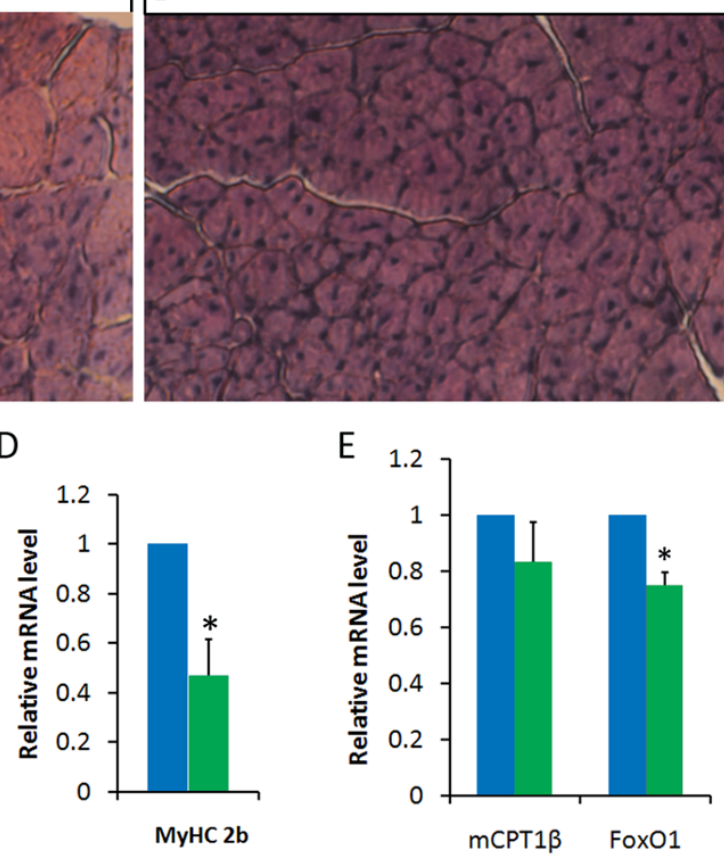

E

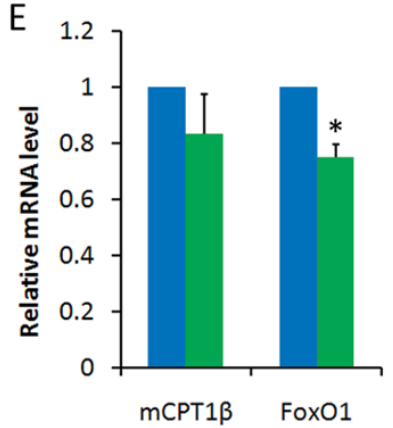

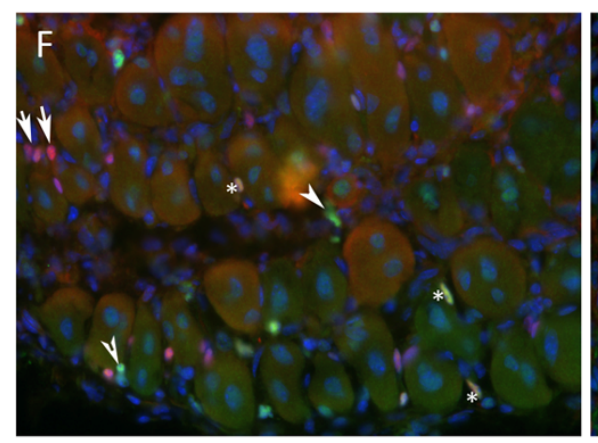
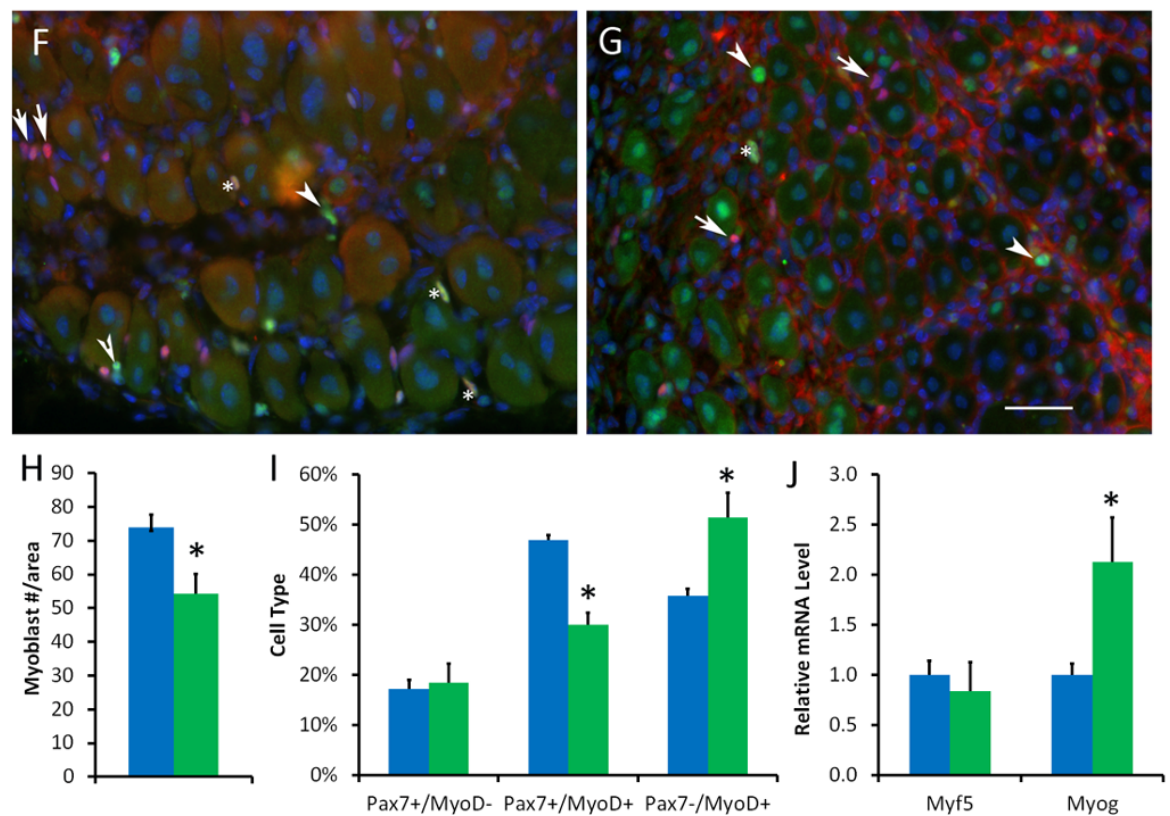

Figure 4 Defective regeneration of skeletal muscles and gene expression patterns in Ppar $\delta$-cKO mice after injury with cardiotoxin. (A) and (B) Tibialis anterior (TA) muscles from six-week-old wild-type and peroxisome proliferator-activated receptor $\delta$ conditional knockout (Ppar $\delta$ cKOmice were injected with cardiotoxin (CTX) to induce injury. The mice were allowed to recover for 14 days before their muscles were harvested and processed for staining. Small and large fibers (indicating regenerating and nonregenerating fibers, respectively) were counted. Scale bars $=50 \mu \mathrm{m}$ for parts (A) and (B) and for parts (F) and (G). (C) Quantification of regenerating and nonregenerating fibers after injury with CTX ( $N=3$ pairs of mice, with five sections taken from each mouse). (D) Relative mRNA expression level showing reduced myosin heavy chain isoform 2b (MyHC-2b) in mutant muscle after injury with CTX (N = 4). (E) Relative mRNA expression levels of Ppar $\delta$ target genes in the TA muscle after injury with $C T X(N=4)$. $(\mathbf{F})$ and $(\mathbf{G})$ Cryosections of regenerating wild-type $(\mathbf{F})$ and mutant $(\mathbf{G})$ mice at day 5 after injury with $C T X$. The sections are labeled with paired-box transcription factor 7 (Pax7) (red), myogenic differentiation antigen 1 (MyoD) (green) and 4', 6diamidino-2-phenylindole (DAPI) (blue). Arrows, arrowheads and asterisks indicate examples of Pax $7^{+} / \mathrm{MyoD}^{-}, \mathrm{Pax} 7^{-} / \mathrm{MyoD}^{+}$and $\mathrm{Pax} 7^{+} / \mathrm{MyoD}^{+}$ myoblasts, respectively. (H) The number of total myoblasts labeled by Pax7 and/or MyoD per unit area counted from 8 to 13 areas. (I) Percentage distribution of $\mathrm{Pax}^{+} / \mathrm{MyoD}^{-}, \mathrm{Pax}^{+} / \mathrm{MyoD}^{+}$and $\mathrm{Pax} 7^{-} / \mathrm{MyoD}^{+}$myoblasts in regenerating wild-type and mutant TA muscles at day 5 after injury with CTX. (J) Relative mRNA expression levels of Myf5 and Myogenin in TA muscles at day 3 after injury with $C T X(N=3)$. ${ }^{*} P<0.05$ by single-tailed Student's t-test. 
myoblasts compared to mature muscles (Figure 1B), these results suggest a critical role of PPAR $\delta$ in satellite cell function in vivo.

\section{Ppar $\delta$-cKO does not alter myosin heavy chain isoforms}

Because Ppar $\delta$ overexpression increases oxidative muscle fiber types [32], we sought to determine whether Ppar -cKO causes any changes in fiber-type distribution. We labeled MyHC protein isoforms with a panel of
mAbs (Figures 5A to 5D). We chose the EDL and SOL muscles to represent fast and slow muscle types, respectively. To overcome potential bias associated regionalized distribution of fiber types within a muscle [45], we enumerated all muscle fibers in the entire muscle (Figures $5 \mathrm{~A}$ to $5 \mathrm{D}$ ). No difference in the percentage of each fiber type was found between mutant and wild-type animals in either the EDL or SOL muscle at six weeks old (Figure 5E). To further determine whether there are

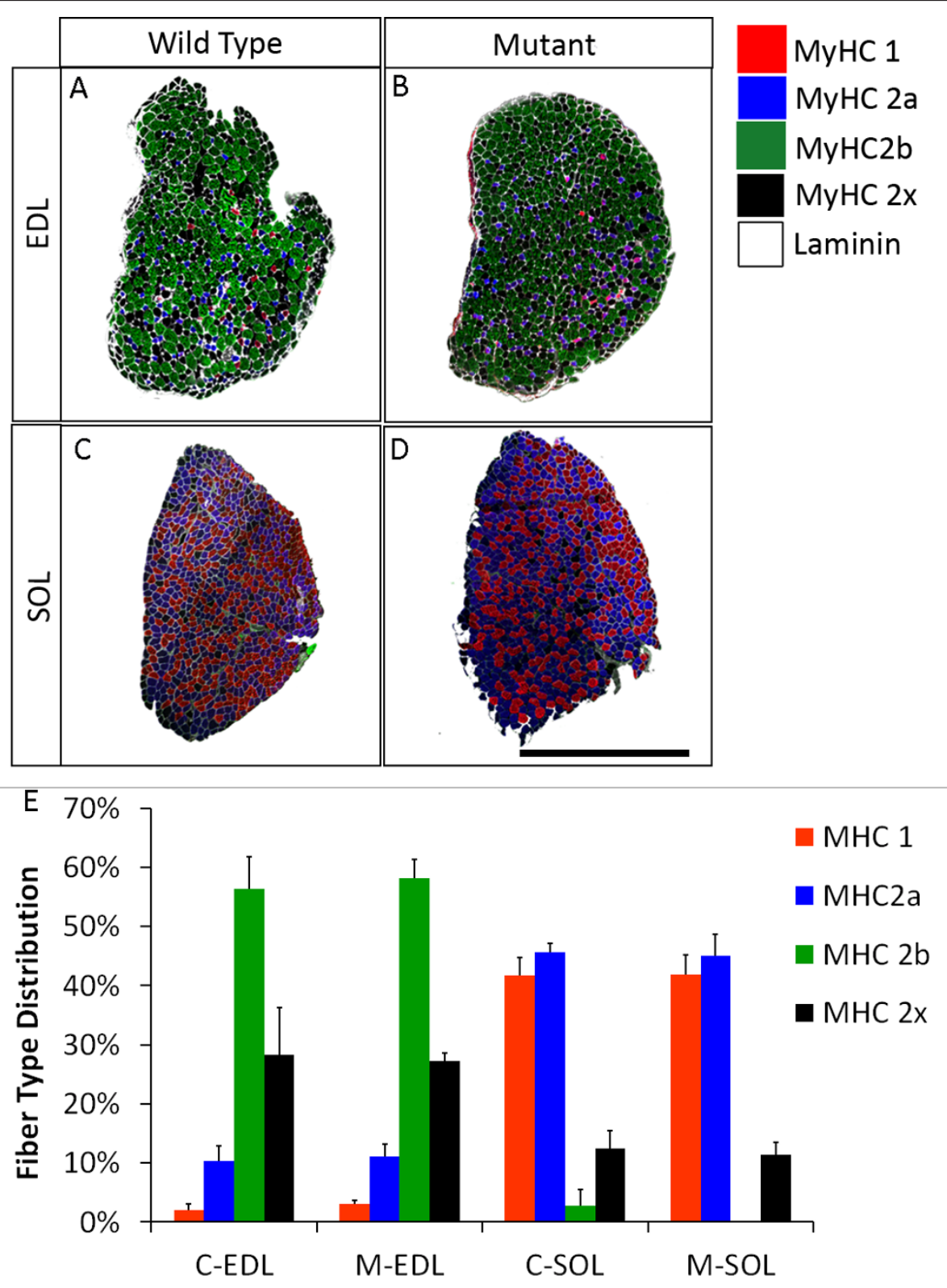

Figure 5 Normal fiber-type distributions in extensor digitorum longus and soleus muscles of six-week-old Ppar $\delta$-cKO mice. (A) through (D) Immunostained sections showing the distribution of fiber types in the extensor digitorum longus (EDL) and soleus (SOL) ("C-" denotes wildtype littermate control and "M-" denotes Ppar $\delta$-cKO): myosin heavy chain isoform 1 (MyHC-1) (red), MyHC-2a (blue), MyHC-2b (green), MyHC-2x (black) and laminin (white). The basal lamina surrounding each fiber is shown. Scale bar $=1 \mathrm{~mm}$. (E) Percentage distribution of each fiber type in the EDL and SOL muscles ( $N=4$ pairs of littermates. 
changes in muscle oxidative metabolism without changing $\mathrm{MyHC}$ isoform expression, we carried out NADHtetrazolium reductase (NADH-TR) staining of the SOL and EDL muscles. NADH-TR staining marks ATPase activity that is correlated to oxidative capacity (type 1 fibers are highly oxidative and darkly stained, type 2a fibers are intermediate fibers and lightly stained and type $2 \mathrm{~b}$ fibers are glycolytic and unstained) (Additional file 6, Figures S5A to S5D). In agreement with our $\mathrm{MyHC}$ isoform staining experiments, there were no differences in NADH activity between the Ppar $\delta$-cKO and wild-type mice in either the EDL or the SOL muscles (Additional file 6, Figures S5E and S5F). These results demonstrate that Ppar $\delta$-cKO does not lead to changes in muscle fiber type or oxidative capacity in young animals.

\section{Old Ppar $\delta$-cKO mice become obese and have impaired glucose clearance}

PPAR $\delta$ is an important regulator of muscle energy metabolism. Therefore, we tested the body weight and insulin sensitivity in young and old mutant mice. Young Ppar $\delta$-cKO mice (two months of age) did not differ significantly in body weight compared to their sex-matched wild-type littermates (Figure 6A). However, older mutant mice (nine months of age) were about $25 \%$ heavier on average than their wild-type littermates (Figure $6 \mathrm{~B})$. Next we measured the rate of insulin-mediated glucose clearance in the mutant and wild-type mice. The amount of glucose in the blood was measured before $(0$ minutes) and 15, 30, 60 and 90 minutes after intraperitoneal injection of $2 \mathrm{~g} / \mathrm{kg}$ glucose (Figures $6 \mathrm{C}$ and 6D). Again, young mice showed no differences in the rate of insulin-stimulated glucose uptake as measured by AUC analysis of the glucose tolerance curves (Figure 6E). Strikingly, older mutant mice showed a reduced rate of glucose uptake; their blood glucose levels spiked higher than those of the wild-type mice and took longer to clear from the blood (Figure 6D), resulting in significant increases in the AUC in every time period measured (Figure 6F). These results suggest that the older mice had developed glucose intolerance and an obese phenotype even when fed a normal diet.

\section{Discussion}

The results produced by our Ppar $\delta$-cKO model establish a previously unappreciated role of PPAR $\delta$ in skeletal muscle progenitor cell proliferation. The specificity of the Ppar $\delta$-cKO mouse model is demonstrated by reduced Ppar $\delta$ mRNA expression in both the skeletal muscle and BAT, known to be derived from Myf5 lineage cells. In contrast, Ppar $\delta$ expression was unchanged in WAT, which is derived from a Myf5-independent lineage [20]. The residual Ppar $\delta$ expression detected in
Ppar $\delta$-cKO whole muscle and BAT $(10 \%$ to $20 \%$ of wild-type levels) is probably due to non-Myf5 lineage cells' residing in these tissues, such as nerve cells (neural branches and Schwann cells), vessel-associated cells (blood, lymph, endothelial and smooth muscle cells) and interstitial connective tissue-associated cells (fibroblasts and white adipocytes). In addition, because Myf5-Cre is expressed in about $90 \%$ of satellite cells [15], a small fraction of $M y f 5^{-}$satellite cells would still have normal levels of Ppar $\delta$ expression. We nevertheless observed proliferative defects in satellite cells in vitro and muscle regeneration in vivo. Further studies using other Cre lines with improved efficiency of Ppar $\delta$ deletion in satellite cells would help to better address the muscle-regenerative defects.

Mice lacking PPAR $\delta$ in their skeletal muscles are born at normal ratios and are viable. These animals do not appear to have any noticeable defects in body weight or response to glucose early in life. There was no difference in total fiber number or percentage of each fiber type in representative slow (SOL) and fast (EDL) muscles. However, old mice (eight to nine months old) were significantly fatter than their wild-type littermates and were found to have developed glucose intolerance. This phenotype in the aged mouse is similar to that reported in another transgenic mouse model in which conditional mutation of Ppar $\delta$ in mature skeletal muscles is mediated by human $\alpha$-skeletal actin promoter-driven Cre in the transgenic mouse [33]. In that mouse model $\left(P p a r \delta^{s k m-/-}\right)$, a reduction in the oxidative capacity and muscle fiber-type switching are also detected, whereas such changes are not evident in the Ppar $\delta$-cKO mouse model used in our study. The discrepancy between these observations may be due to the genetic background and nutrition status (that is, diet composition) of the mice used and the different techniques used for fiber typing. The previous study used qPCR analysis to show increases in $M y H C 1$ and $M y H C 2 b$ transcripts in the gastrocnemius muscle [33]. As many muscle fibers express multiple $M y H C$ transcripts, small changes in these transcripts may not be sufficient to induce fibertype switching [46]. In our current study, we used $\mathrm{MyHC}$ isoform-specific mAbs to unambiguously identify fiber types, and we examined all fibers within the entire muscle to eliminate bias due to regional clustering of specific fiber types within the same muscle. We have therefore provided strong evidence that Ppar $\delta$-cKO does not lead to an overt switch of muscle fiber type in young animals based on $\mathrm{MyHC}$ isoform protein expression.

We show herein that the expression levels of $\operatorname{Pax} 7$ are significantly reduced in the whole muscle of $P$ par $\delta$-cKO mice. Because Pax7 is a satellite cell-specific marker [10], this observation suggests a reduction in satellite 


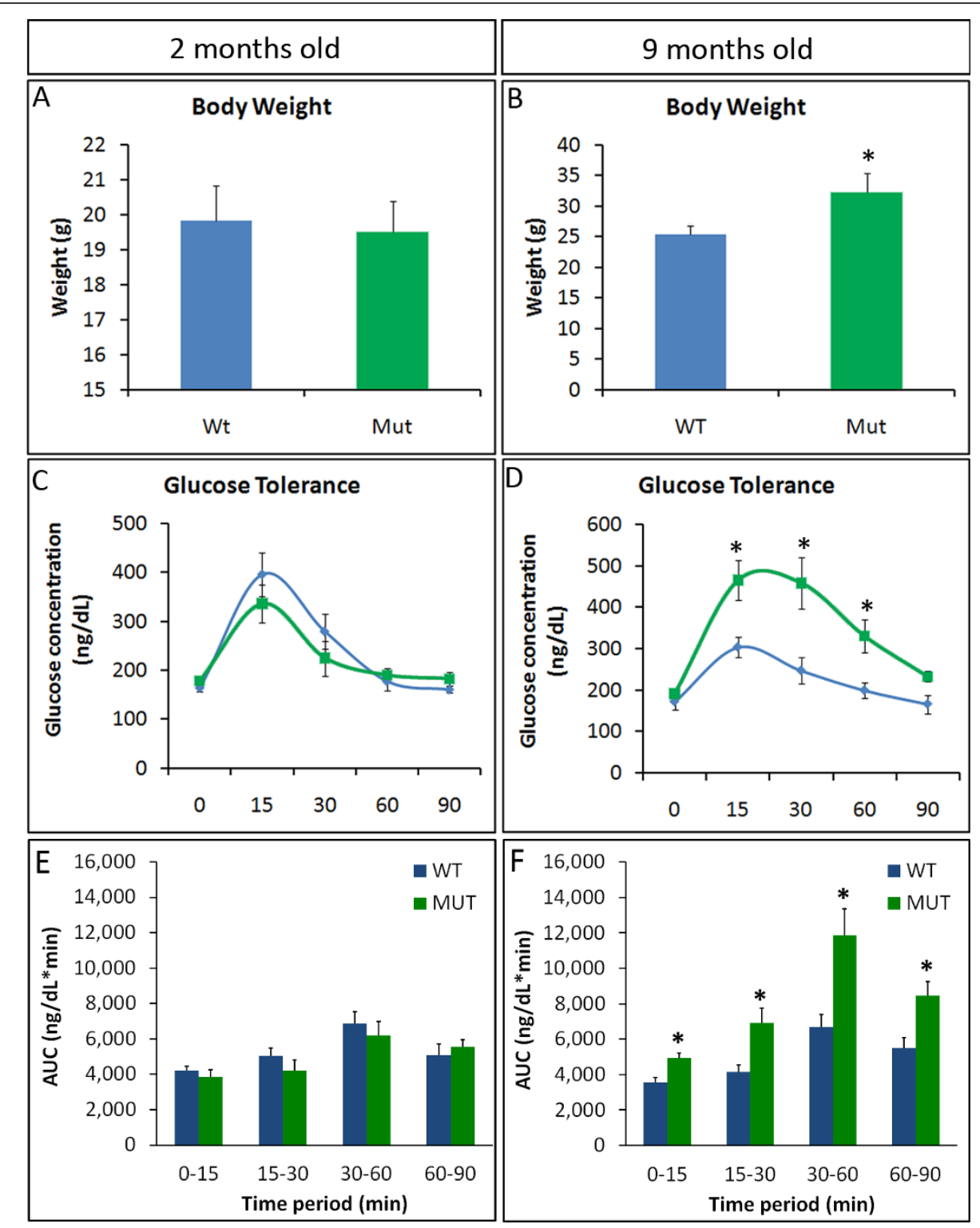

Figure 6 Age-dependent increases in body weight and glucose tolerance in Ppar $\delta$-cKO mice. (A) and (B) Body weights of female wildtype mice and mutant littermates at two and nine months old $(N=6)$. (C) and (D) Blood glucose concentration at different time points following intraperitoneal injection of glucose $(2 \mathrm{~g} / \mathrm{kg})$. The mice were fasted for three hours prior to glucose injection. Glucose concentration was measured using an ACCU-CHEK Active blood glucose meter system (Roche Diagnostics, Indianapolis, IN, USA) ( $N=3$ pairs of female littermates). (E) and (F) Area under the curve (AUC) analysis the of glucose tolerance test results shown in parts (C) and (D), respectively.

cell number, which we confirmed by our later results showing that Ppar $\delta$-cKO mice have fewer satellite cells in vivo. Our single-fiber culture model that mimics satellite cell activation in vivo further demonstrates that there are fewer proliferating satellite cells and increased numbers of differentiating cells in Ppar $\delta$-cKO mice. In vitro growth and proliferation of Ppar $\delta$-cKO satellite cell-derived primary myoblasts were also reduced, as shown by the decreased number of cells expressing the cell proliferation marker Ki67 and the increased population doubling time based on the cell growth curve. Conversely, the PPAR $\delta$ agonist GW501516 stimulates myoblast proliferation. These results provide compelling evidence that PPAR $\delta$ acts to facilitate satellite cell proliferation.

Recent studies have shown that PPAR $\delta$ promotes the proliferation of several cell types. PPAR $\delta$ activation has been shown to increase the proliferation and migration of endothelial progenitors as well as the number of hematopoietic stem cells in the bone marrow $[34,47,48]$. 
In addition, PPAR $\delta$ has been shown to be essential for high glucose-stimulated proliferation of embryonic stem cells [35]. Moreover, PPAR $\delta$ is an important regulator of the proliferation of several cancer cell types $[49,50]$ (older references are reviewed by Peters and Gonzalez [36]). The PPAR $\delta$ antagonists SR13904 and GSK0660, which block PPAR $\delta$ activation, have been shown to reduce cell proliferation $[50,51]$. The role of PPAR $\delta$ in cell proliferation has been shown to be due to its activation of the phosphatidylinositol 3-kinase and AKT pathways $[34,38]$, which has been shown to be important in preventing apoptosis and enhancing cell proliferation by triggering cells to overcome cell-cycle arrest and initiating cell proliferation [52,53]. Importantly, AKT signaling plays critical roles in skeletal muscle progenitor cell function and muscle hypotrophy $[4,5,54]$.

A number of other studies have shown that PPAR $\delta$ promotes differentiation and inhibits (or has no effect on) proliferation in many cell types, particularly keratinocytes, smooth muscle cells, cardiac fibroblasts and several cancer cell lines (extensively reviewed by Peters and Gonzalez [36] and Foreman et al. [55]). Therefore, whether PPAR $\delta$ promotes terminal differentiation or cell proliferation is highly cell type-specific [36]. Intriguingly, investigators in a recent study demonstrated that PPAR $\delta$ can exert its transcriptional activation or repression both ligand-dependently and ligand-independently in a target-specific manner [56]. Such variations in the mode of PPAR $\delta$ action probably account for the paradoxical effects of PPAR $\delta$ in different cell types or even in the same cell type. More research is needed to elucidate how $\operatorname{PPAR} \delta$ regulates satellite cell proliferation and whether it also functions at later stages of myogenesis (see discussion below).

Ppar $\delta$-cKO animals showed delayed muscle regeneration after injury with CTX. We found that, compared to their wild-type littermates, transgenic mice lacking PPAR $\delta$ in the skeletal muscle had a reduced proportion of proliferating myoblasts and that the regenerated fibers were smaller in caliber at both five days and two weeks after CTX injury. These results are consistent with our observations that these animals had fewer satellite cells and that Ppar $\delta$-deficient satellite cells have reduced proliferative potential in vitro. Because satellite cells are responsible for skeletal muscle regeneration, reductions in satellite cell number and defective satellite cell proliferation may have resulted in the observed delay in muscle regeneration. In addition to decreased satellite cell proliferation, loss of PPAR $\delta$ in myofibers may have contributed to the observed defects in muscle regeneration. Moreover, other signaling mechanisms may have compensated for the loss of PPAR $\delta$ in our conditional mutant, leading to completion of muscle regeneration at a later time. Coincidentally, the incidence of sarcopenia (age-related muscle loss) has been shown to correlate with reduced levels of PPAR $\delta$, and pharmacological activation of PPAR $\delta$ has been shown to reduce the incidence of sarcopenia by increasing nuclear accretion in myofibers [57]. These results support the notion that PPAR $\delta$ is important for proper skeletal muscle regeneration in response to injury or daily wear and tear (maintenance) by increasing satellite cell proliferation and promoting fusion of differentiated myocytes in vivo.

We examined the expression levels of several previously identified PPAR $\delta$ target genes to understand how PPAR functions in skeletal muscle and satellite cells. Our results show that the expression of both $m C P T 1 \beta$ and FoxO1 is reduced in mature uninjured muscles of the Ppar $\delta$-cKO mice, suggesting that they are molecular targets of PPAR $\delta$ under resting conditions. Since PPAR $\delta$ has been shown by many groups to be a regulator of oxidative capacity in skeletal muscle [21], it is not surprising that key players in the lipid oxidation pathway would be downregulated after removal of PPAR $\delta$. Interestingly, $m C P T 1 \beta$ expression is not significantly reduced in Ppar $\delta$-cKO muscle at day 5 during regeneration. At this time point, degenerated muscle fibers have not been replaced by new fibers and myoblast proliferation is at the peak stage [8]. This result seems to suggest that $m C P T 1 \beta$ is a target of PPAR $\delta$ in mature resting muscles, but not in proliferating myoblasts. Of all the PPAR $\delta$ target genes we examined, FoxO1 was the only gene whose expression was downregulated in both resting and regenerating muscles of Ppar $\delta$-cKO mice. The downregulation of FoxO1 in Ppar $\delta$-cKO regenerating muscle indicates that FoxO1 may act at downstream of PPAR $\delta$ in regulating myoblast proliferation and inhibiting its differentiation. Indeed, it has been shown that constitutive activation of FoxO1 inhibits myoblast differentiation [44]. However, FoxO1 also acts at later stages of myogenesis, during the fusion of differentiated myocytes into myotubes [58]. These previous studies and our present results suggest that PPAR $\delta$ acts through FoxO1 in both satellite cells and mature muscle fibers but has distinct functions in these cell types. It regulates the proliferation of satellite cells and fusion of muscle fibers. These combined effects of PPAR $\delta$ 's acting through FoxO1 explain the regenerative defects seen in the Ppar $\delta$-cKO muscles.

PPAR $\delta$ has also been implicated in the treatment of degenerative muscle diseases such as Duchenne muscular dystrophy (DMD), which is caused by the mutation of the dystrophin gene $[59,60]$. One research group showed that PPAR $\delta$ activation by the agonist GW501516 increased the expression of utrophin A, a key member of the dystrophin-associated protein complex, in the $\mathrm{C}_{2} \mathrm{C}_{12}$ myoblast cell line [61]. PPAR $\delta$ has 
been suggested to be a direct transcriptional regulator of utrophin $A$ in vivo [43]. Intriguingly, utrophin A overexpression can improve the integrity of the sarcolemma, protect muscles from contraction induced damage and help to alleviate muscle wasting and slow down the disease progression of DMD [62]. Therefore, understanding how PPAR $\delta$ functions in skeletal muscle tissue and its progenitor cells has important implications for muscle regeneration and the treatment of degenerative muscle diseases.

\section{Conclusions}

Our in vivo and in vitro analyses of myogenic lineage specific Ppar $\delta$ gene knockouts demonstrate a critical role of PPAR $\delta$ in satellite cell proliferation and postnatal regeneration of skeletal muscles. In addition, we provide evidence for a role of PPAR $\delta$ in regulating muscle insulin resistance, as indicated by the glucose tolerance test results. However, we were unable to detect overt changes in skeletal muscle fiber types by MyHC isoform-specific antibody labeling. These results not only support the previously established role of PPAR $\delta$ in muscle energy metabolism and insulin sensitivity but also demonstrate a novel role of PPAR $\delta$ in muscle progenitor cell function. These results have implications for the treatment of muscular dystrophies and muscle-wasting conditions by targeting PPAR $\delta$ signaling at the stem cell level.

\section{Additional material}

Additional file 1: Table S1 Primer sequences for quantitative PCR.

Additional file 2: Figure S1 Ppar $\delta$-cKO strategy. (A) Peroxisome proliferator-activated receptor $\delta$ (Ppar $\delta$ ) gene structure with exons numbered sequentially. Note that LoxP sequences are inserted before and after exon 4 encoding the DNA-binding domain of PPAR $\delta$. In the presence of Cre (driven by Myf5 locus in this study), exon 4 is excised, resulting in premature stop in translation and generation of a short, truncated protein without a DNA-binding domain. (B) Representative Western blot showing the relative expression of PPAR $\delta$ protein in the wild-type (WT) and Ppar $\delta$-conditional knockout (Ppar $\delta$-cKO) gastrocnemius muscles. The upper nonspecific band serves as an indicator of the relative amount of total protein loaded onto the gel.

Additional file 3: Figure S2 Relative expression of PPAR $\delta$ target genes in mature noninjured muscles. RNA samples isolated from the tibialis anterior (TA) muscles of six-week old mice were used for quantitative PCR analysis. (A) UCP1. (B) Sirt1. (C) PGC1 $\alpha$. N $=4$ for UCP1 and Sirt1 and $N=6$ for $P G C 1 \alpha$.

Additional file 4: Figure S3 Satellite cell (A) and myonuclei (B) abundance in extensor digitorum longus fibers of wild-type and Ppar $\delta$-cKO mice during postnatal growth at three and five weeks old. Two pairs of mice at each age were used. The satellite cell number was averaged from 30 to 37 fibers, and myonuclei were averaged from 20 to 40 fibers.

Additional file 5: Figure S4 Role of Ppar $\delta$ in primary myoblast proliferation. (A) Relative expression of the peroxisome proliferatoractivated receptor $\delta(P p a r \delta)$ gene in mutant and wild-type myoblasts at passages 3 and $4(N=4)$. (B) Percentage of proliferating cells $\left(K i 67^{+}\right)$in wild-type primary myoblasts at 24 hours after control (dimethyl sulfoxide vehicle) and $100 \mathrm{nM}$ PPARS agonist GW501516 treatments $(N=10)$.

Additional file 6: Figure S5 NADH-tetrazolium reductase staining showing the relative abundance of oxidative fibers in Ppar $\delta$-cKO and wild-type skeletal muscles. Staining shows the three different fiber types. Oxidative fibers (type 1) are darkly stained, intermediate fibers (type 2a) are moderately stained and glycolytic fibers (types $2 \mathrm{~b}$ and $2 \mathrm{x}$ ) are unstained. (A) and (B) Representative images of fast muscles (extensor digitorum longus (EDL)). (C) and (D) Representative images of slow muscles (soleus (SOL)). (E) and (F) Relative nicotinamide adenine dinucleotide, reduced (NADH), intensity levels between peroxisome proliferator-activated receptor $\delta$ (PPAR $\delta$ ) wild-type and PPAR $\delta$-conditional knockout (Ppar $\delta$-cKO) animals at six weeks of age $(N=3)$.

\section{Abbreviations}

BSA: bovine serum albumin; DMEM: Dulbecco's modified Eagle's medium; H \& E: hematoxylin and eosin; mAb: monoclonal antibody; PBS: phosphatebuffered saline; PCR: polymerase chain reaction.

\section{Acknowledgements}

We thank Jun Wu for mouse colony maintenance and other members of the Kuang laboratory for their comments and technical assistance. This project is partially supported by funding from the Muscular Dystrophy Association, the National Institutes of Health and the United Sates Department of Agriculture (to SK). The authors declare no conflict of interests.

\section{Author details}

${ }^{1}$ Department of Animal Sciences, Purdue University, 901 West State Street, West Lafayette, IN 47907, USA. ${ }^{2}$ Program in Gene Function and Expression and Program in Molecular Medicine, University of Massachusetts Medical School, 364 Plantation Street, Worcester, MA 01605, USA. ${ }^{3}$ Center for Cancer Research, Purdue University, 201 S. University Street, West Lafayette, IN 47907, USA

\section{Authors' contributions}

AA carried out the mouse and cell culture studies, analyzed the data and drafted the manuscript. CJ carried out part of the muscle regeneration and immunofluorescence labeling studies. DP conducted the Western blot analysis. YW provided the Ppar-floxedmice, analyzed the data and revised the manuscript. SK conceived, designed and coordinated the study; analyzed the data; and revised the manuscript. All authors read and approved the final manuscript.

\section{Competing interests}

The authors declare that they have no competing interests.

Received: 19 May 2011 Accepted: 1 November 2011 Published: 1 November 2011

\section{References}

1. Zierath JR, Hawley JA: Skeletal muscle fiber type: influence on contractile and metabolic properties. PLOS Biol 2004, 2:e348.

2. Rana ZA, Gundersen K, Buonanno A: Activity-dependent repression of muscle genes by NFAT. Proc Natl Acad Sci USA 2008, 105:5921-5926.

3. Serrano AL, Murgia M, Pallafacchina G, Calabria E, Coniglio P, Lømo T, Schiaffino S: Calcineurin controls nerve activity-dependent specification of slow skeletal muscle fibers but not muscle growth. Proc Natl Acad Sci USA 2001, 98:13108-13113.

4. Bassel-Duby R, Olson EN: Signaling pathways in skeletal muscle remodeling. Annu Rev Biochem 2006, 75:19-37.

5. Glass DJ: PI3 kinase regulation of skeletal muscle hypertrophy and atrophy. Curr Top Microbiol Immunol 2010, 346:267-278.

6. Pavlath GK, Horsley V: Cell fusion in skeletal muscle: central role of NFATC2 in regulating muscle cell size. Cell Cycle 2003, 2:420-423.

7. Tedesco FS, Dellavalle A, Diaz-Manera J, Messina G, Cossu G: Repairing skeletal muscle: regenerative potential of skeletal muscle stem cells. J Clin Invest 2010, 120:11-19. 
8. Charge SB, Rudnicki MA: Cellular and molecular regulation of muscle regeneration. Physiol Rev 2004, 84:209-238.

9. Kuang S, Rudnicki MA: The emerging biology of satellite cells and their therapeutic potential. Trends Mol Med 2008, 14:82-91.

10. Seale P, Sabourin LA, Girgis-Gabardo A, Mansouri A, Gruss P, Rudnicki MA Pax7 is required for the specification of myogenic satellite cells. Cell 2000, 102:777-786.

11. Halevy O, Piestun $Y$, Allouh MZ, Rosser BW, Rinkevich $Y$, Reshef R, Rozenboim I, Wleklinski-Lee M, Yablonka-Reuveni Z: Pattern of Pax7 expression during myogenesis in the posthatch chicken establishes a model for satellite cell differentiation and renewal. Dev Dyn 2004, 231:489-502.

12. Olguin $\mathrm{HC}$, Olwin BB: Pax-7 up-regulation inhibits myogenesis and cell cycle progression in satellite cells: a potential mechanism for selfrenewal. Dev Biol 2004, 275:375-388.

13. Zammit PS, Golding JP, Nagata Y, Hudon V, Partridge TA, Beauchamp JR: Muscle satellite cells adopt divergent fates: a mechanism for selfrenewal? J Cell Biol 2004, 166:347-357.

14. Conboy MJ, Karasov AO, Rando TA: High incidence of non-random template strand segregation and asymmetric fate determination in dividing stem cells and their progeny. PLOS Biol 2007, 5:e102.

15. Kuang S, Kuroda K, Le Grand F, Rudnicki MA: Asymmetric self-renewal and commitment of satellite stem cells in muscle. Cell 2007, 129:999-1010.

16. Shinin V, Gayraud-Morel B, Gomes D, Tajbakhsh S: Asymmetric division and cosegregation of template DNA strands in adult muscle satellite cells. Nat Cell Biol 2006, 8:677-687.

17. Buckingham M, Bajard L, Chang T, Daubas P, Hadchouel J, Meilhac S, Montarras D, Rocancourt D, Relaix F: The formation of skeletal muscle: from somite to limb. J Anat 2003, 202:59-68.

18. Ustanina S, Carvajal J, Rigby P, Braun T: The myogenic factor Myf5 supports efficient skeletal muscle regeneration by enabling transient myoblast amplification. Stem Cells 2007, 25:2006-2016.

19. Gayraud-Morel B, Chrétien F, Flamant P, Gomès D, Zammit PS, Tajbakhsh S: A role for the myogenic determination gene Myf5 in adult regenerative myogenesis. Dev Biol 2007, 312:13-28.

20. Seale P, Bjork B, Yang W, Kajimura S, Chin S, Kuang S, Scimè A, Devarakonda S, Conroe HM, Erdjument-Bromage H, Tempst P, Rudnicki MA, Beier DR, Spiegelman BM: PRDM16 controls a brown fat/skeletal muscle switch. Nature 2008, 454:961-967.

21. Wang YX: PPARs: diverse regulators in energy metabolism and metabolic diseases. Cell Res 2010, 20:124-137.

22. Lefebvre P, Chinetti G, Fruchart JC, Staels B: Sorting out the roles of PPARa in energy metabolism and vascular homeostasis. J Clin Invest 2006, 116:571-580.

23. Semple RK, Chatterjee VK, O'Rahilly S: PPARy and human metabolic disease. J Clin Invest 2006, 116:581-589.

24. Barish GD, Narkar VA, Evans RM: PPARס: a dagger in the heart of the metabolic syndrome. J Clin Invest 2006, 116:590-597.

25. Girroir EE, Hollingshead HE, He P, Zhu B, Perdew GH, Peters JM: Quantitative expression patterns of peroxisome proliferator-activated

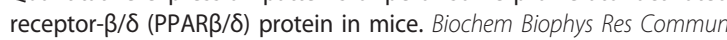
2008, 371:456-461

26. Escher P, Braissant O, Basu-Modak S, Michalik L, Wahli W, Desvergne B: Rat PPARs: quantitative analysis in adult rat tissues and regulation in fasting and refeeding. Endocrinology 2001, 142:4195-4202.

27. Michalik L, Auwerx J, Berger JP, Chatterjee VK, Glass CK, Gonzalez FJ, Grimaldi PA, Kadowaki T, Lazar MA, O'Rahilly S, Palmer CNA, Plutzky J, Reddy JK, Spiegelman BM, Staels B, Wahli W: International Union of Pharmacology. LXI. Peroxisome proliferator-activated receptors. Pharmacol Rev 2006, 58:726-741.

28. Shearer BG, Hoekstra WJ: Recent advances in peroxisome proliferatoractivated receptor science. Curr Med Chem 2003, 10:267-280.

29. Oliver WR Jr, Shenk JL, Snaith MR, Russell CS, Plunket KD, Bodkin NL, Lewis MC, Winegar DA, Sznaidman ML, Lambert MH, Xu HE, Sternbach DD, Kliewer SA, Hansen BC, Willson TM: A selective peroxisome proliferatoractivated receptor $\delta$ agonist promotes reverse cholesterol transport. Proc Natl Acad Sci USA 2001, 98:5306-5311.

30. Napal L, Marrero PF, Haro D: An intronic peroxisome proliferator-activated receptor-binding sequence mediates fatty acid induction of the human carnitine palmitoyltransferase 1A. J Mol Biol 2005, 354:751-759.
31. Luquet S, Lopez-Soriano J, Holst D, Fredenrich A, Melki J, Rassoulzadegan M, Grimaldi PA: Peroxisome proliferator-activated receptor $\delta$ controls muscle development and oxidative capability. FASEB J 2003, 17:2299-2301.

32. Wang YX, Zhang CL, Yu RT, Cho HK, Nelson MC, Bayuga-Ocampo CR, Ham J, Kang H, Evans RM: Regulation of muscle fiber type and running endurance by PPARS. PLOS Biol 2004, 2:e294.

33. Schuler M, Ali F, Chambon C, Duteil D, Bornert JM, Tardivel A, Desvergne B, Wahli W, Chambon P, Metzger D: PGC1a expression is controlled in skeletal muscles by PPAR $\beta$, whose ablation results in fiber-type switching, obesity, and type 2 diabetes. Cell Metab 2006, 4:407-414.

34. Han JK, Lee HS, Yang HM, Hur J, Jun SI, Kim JY, Cho CH, Koh GY, Peters JM, Park KW, Cho HJ, Lee HY, Kang HJ, Oh BH, Park YB, Kim HS: Peroxisome proliferator-activated receptor- $\delta$ agonist enhances vasculogenesis by regulating endothelial progenitor cells through genomic and nongenomic activations of the phosphatidylinositol 3-kinase/Akt pathway. Circulation 2008, 118:1021-1033.

35. Kim $\mathrm{YH}$, Han $\mathrm{HJ}$ : High-glucose-induced prostaglandin $\mathrm{E}_{2}$ and peroxisome proliferator-activated receptor $\delta$ promote mouse embryonic stem cell proliferation. Stem Cells 2008, 26:745-755.

36. Peters JM, Gonzalez FJ: Sorting out the functional role(s) of peroxisome proliferator-activated receptor- $\beta / \delta(\operatorname{PPAR} \beta / \delta)$ in cell proliferation and cancer. Biochim Biophys Acta 2009, 1796:230-241.

37. Simonini MV, Polak PE, Boullerne Al, Peters JM, Richardson JC, Feinstein DL: Regulation of oligodendrocyte progenitor cell maturation by PPARס: effects on bone morphogenetic proteins. ASN Neuro 2010, 2:e00025.

38. Wang D, Wang H, Guo Y, Ning W, Katkuri S, Wahli W, Desvergne B, Dey SK, DuBois RN: Crosstalk between peroxisome proliferator-activated receptor $\delta$ and VEGF stimulates cancer progression. Proc Natl Acad Sci USA 2006, 103:19069-19074.

39. Barak Y, Liao D, He W, Ong ES, Nelson MC, Olefsky JM, Boland R, Evans RM: Effects of peroxisome proliferator-activated receptor $\delta$ on placentation, adiposity, and colorectal cancer. Proc Natl Acad Sci USA 2002, 99:303-308.

40. Tallquist MD, Weismann KE, Hellström M, Soriano P: Early myotome specification regulates PDGFA expression and axial skeleton development. Development 2000, 127:5059-5070.

41. Rosenblatt JD, Lunt Al, Parry DJ, Partridge TA: Culturing satellite cells from living single muscle fiber explants. In vitro Cell Dev Biol Anim 1995, 31:773-779.

42. Nahlé Z, Hsieh M, Pietka T, Coburn CT, Grimaldi PA, Zhang MQ, Das D, Abumrad NA: CD36-dependent regulation of muscle FoxO1 and PDK4 in the PPAR $\delta / \beta$-mediated adaptation to metabolic stress. J Biol Chem 2008, 283:14317-14326.

43. Wagner KD, Wagner $\mathrm{N}$ : Peroxisome proliferator-activated receptor $\beta / \delta$ (PPAR $\beta / \delta$ ) acts as regulator of metabolism linked to multiple cellular functions. Pharmacol Ther 2010, 125:423-435.

44. Kitamura T, Kitamura YI, Funahashi Y, Shawber CJ, Castrillon DH, Kollipara R, DePinho RA, Kitajewski J, Accili D: A Foxo/Notch pathway controls myogenic differentiation and fiber type specification. J Clin Invest 2007, 117:2477-2485.

45. Wang LC, Kernell D: Recovery of type I fiber regionalization in gastrocnemius medialis of the rat after reinnervation along original and foreign paths, with and without muscle rotation. Neuroscience 2002, 114:629-640.

46. Waddell JN, Zhang P, Wen Y, Gupta SK, Yevtodiyenko A, Schmidt JV, Bidwell CA, Kumar A, Kuang S: Dlk1 is necessary for proper skeletal muscle development and regeneration. PLoS One 2010, 5:e15055.

47. He T, Lu T, d'Uscio LV, Lam CF, Lee HC, Katusic ZS: Angiogenic function of prostacyclin biosynthesis in human endothelial progenitor cells. Circ Res 2008, 103:80-88.

48. Piqueras $L$, Reynolds AR, Hodivala-Dilke KM, Alfranca A, Redondo JM, Hatae T, Tanabe T, Warner TD, Bishop-Bailey D: Activation of PPARß/ס induces endothelial cell proliferation and angiogenesis. Arterioscler Thromb Vasc Biol 2007, 27:63-69.

49. Kannan-Thulasiraman P, Seachrist DD, Mahabeleshwar GH, Jain MK, Noy N: Fatty acid-binding protein 5 and PPAR $\beta / \delta$ are critical mediators of epidermal growth factor receptor-induced carcinoma cell growth. J Biol Chem 2010, 285:19106-19115.

50. Zaveri NT, Sato BG, Jiang F, Calaoagan J, Laderoute KR, Murphy BJ: A novel peroxisome proliferator-activated receptor $\delta$ antagonist, SR13904, has 
anti-proliferative activity in human cancer cells. Cancer Biol Ther 2009, 8:1252-1261.

51. Wagner KD, Benchetrit M, Bianchini L, Michiels JF, Wagner N: Peroxisome proliferator-activated receptor $\beta / \delta$ (PPAR $\beta / \delta$ ) is highly expressed in liposarcoma and promotes migration and proliferation. J Pathol 2011, 224:575-588.

52. Ramaswamy S, Nakamura N, Vazquez F, Batt DB, Perera S, Roberts TM, Sellers WR: Regulation of $G_{1}$ progression by the PTEN tumor suppressor protein is linked to inhibition of the phosphatidylinositol 3-kinase/Akt pathway. Proc Natl Acad Sci USA 1999, 96:2110-2115.

53. Kandel ES, Skeen J, Majewski N, Di Cristofano A, Pandolfi PP, Feliciano CS, Gartel A, Hay N: Activation of Akt/protein kinase B overcomes a $G_{2} / M$ cell cycle checkpoint induced by DNA damage. Mol Cell Biol 2002, 22:7831-7841

54. Chakravarthy MV, Abraha TW, Schwartz RJ, Fiorotto ML, Booth FW: Insulinlike growth factor-l extends in vitro replicative life span of skeletal muscle satellite cells by enhancing $G_{1} / S$ cell cycle progression via the activation of phosphatidylinositol 3'-kinase/Akt signaling pathway. J Biol Chem 2000, 275:35942-35952.

55. Foreman JE, Sharma AK, Amin S, Gonzalez FJ, Peters JM: Ligand activation of peroxisome proliferator-activated receptor- $\beta / \delta(\operatorname{PPAR} \beta / \delta)$ inhibits cell growth in a mouse mammary gland cancer cell line. Cancer Lett 2010, 288:219-225.

56. Adhikary T, Kaddatz K, Finkernagel F, Schönbauer A, Meissner W, Scharfe M, Jarek M, Blöcker H, Müller-Brüsselbach S, Müller R: Genomewide analyses define different modes of transcriptional regulation by peroxisome

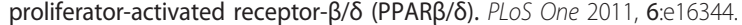

57. Giordano C, Rousseau AS, Wagner N, Gaudel C, Murdaca J, Jehl-Piétri C, Sibille B, Grimaldi PA, Lopez P: Peroxisome proliferator-activated receptor $\beta$ activation promotes myonuclear accretion in skeletal muscle of adult and aged mice. Pflügers Arch 2009, 458:901-913.

58. Bois PRJ, Grosveld GC: FKHR (FOXO1a) is required for myotube fusion of primary mouse myoblasts. EMBO J 2003, 22:1147-1157.

59. Hoffman EP, Brown RH Jr, Kunkel LM: Dystrophin: the protein product of the Duchenne muscular dystrophy locus. Cell 1987, 51:919-928.

60. Zubrzycka-Gaarn EE, Bulman DE, Karpati G, Burghes AH, Belfall B, Klamut HJ, Talbot J, Hodges RS, Ray PN, Worton RG: The Duchenne muscular dystrophy gene product is localized in sarcolemma of human skeletal muscle. Nature 1988, 333:466-469.

61. Miura P, Chakkalakal JV, Lunde J, Shaver A, Belanger G, Jasmin BJ: Activation of PPAR $\delta$ stimulates utrophin A expression in skeletal muscle cells. FASEB J 2007, 21:A1301-A1302.

62. Miura P, Chakkalakal JV, Boudreault L, Bélanger G, Hébert RL, Renaud JM Jasmin BJ: Pharmacological activation of PPAR $\beta / \delta$ stimulates utrophin A expression in skeletal muscle fibers and restores sarcolemmal integrity in mature $m d x$ mice. Hum Mol Genet 2009, 18:4640-4649.

doi:10.1186/2044-5040-1-33

Cite this article as: Angione et al:: PPAR $\delta$ regulates satellite cell proliferation and skeletal muscle regeneration. Skeletal Muscle 2011 1:33.

\section{Submit your next manuscript to BioMed Central and take full advantage of:}

- Convenient online submission

- Thorough peer review

- No space constraints or color figure charges

- Immediate publication on acceptance

- Inclusion in PubMed, CAS, Scopus and Google Scholar

- Research which is freely available for redistribution 